\title{
A Cultura da Audiovisualidade: Contribuições Nacionais e Internacionais
}

Há tempos que as narrativas fazem parte da vivência humana e, de certo modo, também a definem por meio de suas relações na ação do relato, pela história e pela criação de uma trama que nos motiva a exercer uma infinita capacidade de expressão. Seja a narrativa jornalística ou a ficcional do cinema (e, até mesmo, a tênue linha que separa aquilo que se entende por verídico ou não), fato é que a comunicação torna-se, em muitos sentidos, quase um verbete sinonímico da importância das narrativas no cotidiano social.

Mais forte ainda se mostra o valor dessas narrativas quando as visualizamos no campo da cultura audiovisual. É nesse específico espaço que elas potencializam sua expressividade e (por que não?) a necessidade humana de contar, relatar e dramatizar. É na cultura audiovisual que as narrativas ganham corpo, vivacidade e uma existência praticamente autônoma. E está no campo audiovisual aquilo que mais nos torna seres narrativos: a capacidade de criar imagens que tenham um sentido único por meio das cores, da fotografia, dos ângulos, dos movimentos, das texturas, das músicas, da cultura da oralidade e de produções sonoras presentes em filmes, documentários, telenovelas, minisséries, webséries e tantas outras obras audiovisuais.

Justamente por entender a relevância das pesquisas no âmbito da cultura audiovisual é que a revista "Ação Midiática - Estudos em Comunicação, Sociedade e Cultura" se dedica a esse tema em sua oitava edição. A finalidade desta edição é apresentar textos que tratem de cinema em seus mais variados gêneros, de ficção seriada televisiva, de narrativas transmídias e de outras formas da cultura audiovisual ligadas ao campo da comunicação. Neste dossiê em específico, trabalhos vinculados a questões como adaptações, processos produtivos e narrativos, matrizes culturais e representações sociais e políticas, estética da imagem, estética cinematográfica, metodologias de análises, formatos e estilística da teledramaturgia, regimes estéticos de interação, estudos de produção e recepção, entre outros exemplos, são apresentados no decorrer da publicação.

Desse modo, a tônica do dossiê "Comunicação e Cultura Audiovisual” está centrada em um importante apanhado das reflexões e investigações de pesquisadores reconhecidos no campo dentro e fora do Brasil. Esta edição obteve significativa participação internacional: autores dos Estados Unidos, do Peru, da Espanha, do México, da Argentina e de Portugal são alguns dos exemplos da internacionalização e da presença do periódico para além das nossas fronteiras. A publicação, ligada ao Programa de Pós-Graduação em Comunicação da Universidade Federal do Paraná, ainda conta neste dossiê com a coorganização do Núcleo de Estudos em Ficção Seriada (NEFICS), pertencente à mesma instituição e vinculado também ao CNPq.

Como mostra de tal internacionalização, o dossiê é aberto com o trabalho "Producing Brazilianess for Global Audiences: The case of Sex and the City", dos convidados Samantha 
Nogueira Joyce (Indiana University South Bend) e Antonio C. La Pastina (Texas A\&M University). $\mathrm{O}$ artigo desses professores brasileiros, mas que atuam nos Estados Unidos em pesquisas de cunho midiático, enfoca a representação social da mulher brasileira e também do Brasil a partir da série estadunidense Sex and the City (HBO).

Ainda na linha de estudos sobre gênero e cultura audiovisual, a convidada é a professora peruana Giuliuna Cassano Iturri (Pontificia Universidad Católica del Perú), que traz o artigo "Mirando la Telenovela desde el Género. Natacha: De la Domesticidad a la Agencia". O trabalho aborda importantes contribuições na discussão das produções Natacha (1970) e Yo no me llamo Natacha (2010), visualizadas sob os modelos e os estereótipos do gênero feminino.

O último autor convidado do dossiê é o professor espanhol Lorenzo Vilches Manterola (Universidad Autónoma de Barcelona), que, com a investigação "Parodia y Reflexividad en Transmedia", traz uma singular contribuição aos estudos em cultura audiovisual no terreno das mídias digitais, especificamente no campo das narrativas transmidiáticas e dos novos atores e sistemas de produção e consumo comunicacional.

Ainda compõe o dossiê o artigo "Modelo Semiótico da Telenovela Brasileira Multiplataforma", da doutoranda Ligia Maria Prezia Lemos (USP), que trata da comunicação estética por meio de um breve exercício de decomposição estrutural e da discussão de temas arquetípicos relacionados à disputa entre os sexos. O trabalho "Pelas Esquinas da Vida: A (Des)Construção da Imagem de Prostitutas na Série O Negócio”, escrito pela doutora Telma Johnson (UFJF) e pela graduanda em Comunicação Social Gabriella Cristina do Nascimento Ribeiro (UFJF), analisa a construção da imagem de garotas de programa nessa série televisiva exibida pelo canal HBO sob a ótica dos enquadramentos e das particularidades da prostituição representada na TV.

Jussara Peixoto Maia (UFBA/Faculdade Social da Bahia), em "Programas de Variedades na TV e Entretenimento: Investigando o Rastro dessas Relações", apresenta um debate a respeito da relação entre programas de variedades televisivos e a categoria do entretenimento, considerando a história da televisão brasileira em uma análise cultural em interface com a comunicação. No artigo "Televisualidades Latino-americanas em Território On-line: Representação Cultural no site da TAL", a mestra Michele Dacas (UFSM) aponta algumas reflexões acerca da América Latina - vista como uma região cultural e discursivamente heterogênea - e observa como são configuradas as representações da AL na WebTV Televisión América Latina (TAL).

Em “A(s) Guerra(s) dos Meninos: uma Adaptação, Vários Sentidos”, a mestranda Morgani Guzzo (Unicentro) e o doutor Rodolfo Rorato Londero (UEL) investigam a análise da adaptação do livro-reportagem "A Guerra dos Meninos", do jornalista Gilberto Dimenstein (1994), para o documentário homônimo dirigido por Sandra Werneck (1991). E, fechando o 
dossiê, a pesquisa do doutorando Guilherme Moreira Fernandes (UFRJ/UFJF), com o título "Lésbicas na Telenovela O Rebu: O Romance entre Glorinha e Roberta", traz à tona a discussão a respeito dessas personagens e a pergunta "Qual é o papel da mulher lésbica em telenovela brasileira durante o regime militar?".

Na seção Demanda Contínua a visão de importantes autores internacionais também se faz presente. $\mathrm{O}$ artigo "\#noalospluris y \#menospluris: Las Diferencias entre un Movimiento Ciudadano y un Movimiento Oportunista", dos professores mexicanos Rocío Abascal Mena, Erick López Ornelas e Sergio Zepeda Hernández (todos vinculados à Universidad Nacional Autónoma de México), apresenta uma análise quantitativa de tweets que foram promovidos por diferentes atores políticos entre 2010 e 2014, seguindo a metodologia de Análise de Redes Sociais (ARS). Por sua vez, o trabalho "Movimiento Juvenil YoSoy132: 'El Cisne Negro Mexicano' Frente a los Monopolios Mediáticos (Julio-2012/Marzo-2013)”, do pesquisador mexicano Hugo Sánchez Gudiño (Universidad Nacional Autónoma de México), busca a reflexão por meio das questões que envolvem a comunicação e a política e a relação dessas áreas com a regulação da mídia em seu país.

Os investigadores argentinos Gabriela Bard Wigdor (Universidad Nacional de Córdoba) e Alexis Rasftopolo (Universidad Nacional de Misiones) colaboram, por meio da publicação "Género, Comunicación y Cultura en la Argentina Post 2001: El Caso de las Mujeres de Bajada San José de Córdoba", discutindo as práticas de participação comunitária das mulheres da comunidade da Baixada São José (parte do bairro popular Maldonado, da Cidade de Córdoba, na Argentina), vinculadas ao direito à comunicação e à cultura.

O artigo "Humor no Blog do Professor Hariovaldo", da doutora Regina Rossetti (USCS) e do mestre Cristian Boragan (USCS), problematiza o jornalismo político e eleitoral e traz como objeto de estudo o blog do personagem Hariovaldo de Almeida Prado, isto é, um blog político voltado ao humor e que realiza trocas com materiais informativos praticados na web. E, encerrando os artigos apresentados nesta edição, a pesquisa do doutor Marco Túlio de Sousa (UEMG), "Narrativas do (Con-)vencer: Testemunhos de Fracasso e Sucesso da Igreja Universal na sua Programação Televisiva em Minas Gerais", aponta a existência de uma "arquitetura narrativa" comum a todos os programas que compõem a Programação IURD: as "narrativas de fracasso" atreladas às "narrativas de sucesso" que, por sua vez, são mediadas pelos comentários dos pastores.

As resenhas também acompanham o tema do dossiê ao terem em comum a discussão da televisão no contexto do nosso continente. Em "Da América Latina para o mundo: a cultura televisiva para além das fronteiras em um mercado glocal", o mestrando Anderson Lopes da Silva (UFPR) resenha a obra "Latin American Television Industries" (2013), do australiano John Sinclair e do estadunidense Joseph Straubhaar. A obra "A Memória Televisiva como produto 
cultural: um estudo de caso das telenovelas do Canal Viva" (2014), do brasileiro Julio Cesar Fernandes, é resenhada pela mestranda Priscila Chéquer (UFBA) em "Nostalgia, Memória e Mediação Sociocultural: Desvendando a Importância da Memória Televisiva a partir das Telenovelas Veiculadas no Canal Viva”.

O livro "Las telenovelas puerta adentro: el discurso social de la telenovela chilena" (2003), do chileno Eduardo Santa Cruz, é apresentado na resenha "Reflexões sobre o Discurso Social das Telenovelas no Contexto Latino-americano", do mestre André Richard Durante Vieira (UFPR). E a resenha "Televisão peruana em 14 perspectivas", do doutorando Paulo Negri Filho (Unisinos), finaliza esta seção com as questões sobre a interface da comunicação e da cultura audiovisual mostradas na obra "Televisión: 14 formas de mirarla" (2010), organizada pela peruana Giuliana Cassano.

Fechando a oitava edição, a doutoranda Elaine Javorski (Universidade de Coimbra) colabora com a entrevista "Brasil e Portugal: intercâmbio acadêmico sobre ficção televisiva", trazendo o depoimento da doutora portuguesa Isabel Ferin (Universidade de Coimbra) que traça um minucioso e interessante relato sobre as experiências das investigações do campo audiovisual nos dois países - um tema que também se liga diretamente a este dossiê. A entrevistada é uma pesquisadora de relevância no cenário e, entre outros projetos, coordenou de 2006 a 2013 a seção portuguesa do projeto internacional Observatório Ibero-americano da Ficção Televisiva (Obitel).

Nessa miríade de investigações e múltiplas visões, convidamos você, leitor(a), a também se envolver nesse universo da cultura audiovisual, um mundo repleto de imagens e sons que traduzem o "nosso mundo" em forma de narrativas.

Uma ótima leitura!

Anderson Lopes da Silva e Celsi Brönstrup Silvestrin Editores 